\title{
Active avoidance in the laboratory rat following lesions of the dorsal or ventral caudate nucleus*
}

\author{
ROBERT J. KIRKBY \\ College of Paramedical Studies, Glebe N.S.W., Australia \\ and \\ STEPHEN POLGAR \\ University of Sydney, N.S.W., Australia
}

\begin{abstract}
Active avoidance learning in rats with lesions of the ventral or dorsal caudate nucleus was investigated in both one-way and two-way avoidance situations. Performance was measured under various levels of shock and conditions of food deprivation. Winocur and Mills (1969) hypothesized that the learning of active avoidance problems was disrupted by lesions of the ventral aspect of the caudate nucleus but not by dorsal lesions. In the present study, rats with lesions of the ventral caudate were not more deficient than rats with lesions of the dorsal caudate in learning to avoid. Under some conditions, dorsal lesion rats were significantly more impaired than ventral lesion rats. These findings, taken with other recent reports, suggest that the Winocur and Mills hypothesis should be rejected.
\end{abstract}

Following lesions of the caudate nucleus, a wide variety of learning tasks are disrupted. One of the best documented of these is active avoidance learning (Kirkby, 1969, 1970). Caudate-damaged rats, cats, dogs, and monkeys have been found impaired in learning active avoidance problems requiring two-way, one-way, or simpler operant-type responding (Green, Beatty, \& Schwartzbaum, 1967; Kirkby \& Kimble, 1968; Romanovskaya, 1957; Thompson \& Mettler, 1963; Turner, 1954).

Winocur and Mills (1969) reported that rats with lesions of the caudate nucleus were not significantly impaired in learning a one-way active avoidance task. The absence of deficit, they suggested, was associated with the specific location of the caudate lesion. Winocur and Mills $(1969,1970)$ hypothesized that lesions restricted to the dorsal aspect of the caudate nucleus did not disrupt active avoidance learning, but that avoidance learning was impaired following damage to the ventral areas of the caudate. Unfortunately, this hypothesis was not experimentally tested by Winocur and Mills (1969). They lesioned the dorsal caudate, found no significant deficits, and, on their interpretation of earlier findings, assumed that ventral lesions would result in deficits. It seems clear that without a confirmatory ventral lesion group, Winocur and Mills's findings are open to more than one explanation. As was suggested by Winocur and Mills $(1969,1970)$, the unimpaired performance of rats with lesions of the dorsal caudate might have been associated with the specific area of damage.

*This work was supported in part by funds from the New South Wales Department of Health. Some of the findings reported in this paper were contained in an empirical thesis submitted by S. Polgar to the Department of Psychology, University of Sydney. Reprint requests should be addressed to R. J. Kirkby, College of Paramedical Studies, Box K348, P.O Haymarket, N.S.W., Australia, 2000.
Alternatively, it could be that the site of lesion was of no importance and the lack of deficit in the dorsal lesion rats was associated with another variable, such as the size of the lesion, the method of statistical analysis, or some factor of the experimental procedure.

The aim of the first experiment in this study was to test the hypothesis of Winocur and Mills with particular regard to the role of the anterodorsal caudate nucleus in avoidance learning. One-way active avoidance was investigated in rats with lesions of either the dorsal aspect or the ventral aspect of the caudate nucleus.

\section{EXPERIMENT I}

\section{Method}

The Ss were 39 male Wistar rats, supplied by the C.S.I.R.O. The animals were approximately 120 days old at the time of surgery. Ten Ss received bilateral lesions in the dorsal regions of the caudate-putamen complex, 9 rats received bilateral lesions in the ventral caudate-putamen complex, 10 rats received bilateral lesions of the frontal cortex, and 10 rats served as unoperated controls. The animals were housed 4-5 per cage, with free access to food and water.

The rats were anesthetized with sodium pentobarbital, IP $(60 \mathrm{mg} / \mathrm{kg})$. A tropine sulfate was administered preoperatively to reduce salivation. For the dorsal caudate lesions, the electrode was placed $2.2 \mathrm{~mm}$ anterior to the bregma, $2.5 \mathrm{~mm}$ lateral to the midline, and $5.0 \mathrm{~mm}$ below the surface of the skull. The coordinates for the ventral caudate lesions were A, $2.0 \mathrm{~mm}$; L, $2.7 \mathrm{~mm}$; and $\mathrm{V}, 7.5 \mathrm{~mm}$. The electrode placements for the cortical lesions were $\mathrm{A}, 3.2 \mathrm{~mm} ; \mathrm{L}, 2.5 \mathrm{~mm}$; and V, $1.5 \mathrm{~mm}$. The tissue was destroyed electrolytically by applying a $1.5-\mathrm{mA}$ current for $30 \mathrm{sec}$ for the caudate lesions and for $60 \mathrm{sec}$ for the cortical lesions. The cathodal electrode was clipped to the fascia at the edge of the scalp incision. No postoperative medication was administered.

The avoidance apparatus consisted of two similar Plexiglas compartments each $30 \times 12 \times 30 \mathrm{~cm}$ high. These two compartments were connected longitudinally by an $8 \times 10 \mathrm{~cm}$ opening, covered by a black wooden guillotine door. The floors 
Table 1

One-Way Active Avoidance Testing

\begin{tabular}{lccr}
\hline \multicolumn{1}{c}{ Group } & $\mathrm{N}$ & Mean & SD \\
\hline \multicolumn{4}{c}{ Number } \\
of & Avoidances in 50 Trials & \\
Unoperated & 10 & 36.3 & 4.6 \\
Frontal Cortex & 10 & 38.3 & 4.5 \\
Ventral Caudate & 9 & 34.2 & 7.1 \\
Dorsal Caudate & 10 & 28.5 & 11.3 \\
& Number & of Trials to Criterion & \\
Unoperated & 10 & 30 & 4.0 \\
Frontal Cortex & 10 & 31 & 11.0 \\
Ventral Caudate & 9 & 39 & 14.1 \\
Dorsal Caudate & 10 & 47 & 12.8 \\
\hline
\end{tabular}

of the compartments were made of steel rods $(.5 \mathrm{~cm}$ in diam, $1 \mathrm{~cm}$ apart) connected to a constant current stimulator. A speaker, producing a $14,000-\mathrm{cps}$ tone, was placed $10 \mathrm{~cm}$ above the center of the apparatus.

So that the testing procedure could be carried out "blindly," the Ss were renumbered and coded with colored tail markings prior to testing. Avoidance training commenced 15-25 days after surgery. At the beginning of the first session, each $\mathrm{S}$ was allowed $5 \mathrm{~min}$ to explore the apparatus. At the end of this time, the $\mathrm{S}$ was placed in the shock compartment. Five seconds later, the guillotine door between the compartments was opened and the tone activated (CS), and $5 \mathrm{sec}$ after this a $1.0-\mathrm{mA}$ current was passed through the grid floor of the shock compartment (UCS). If the $S$ crossed to the safe compartment during the CS-UCS interval, the response was scored as a successful avoidance. The $S$ was left in the safe compartment for 30 sec. Fifty such trials were given, 10 per day for 5 successive days. Two measures of performance were tabulated: the number of successful avoidances and the trials taken to reach a criterion of nine successful avoidances in any one day of testing. All testing was carried out in the evening, between 6 and 9 p.m.

\section{Results}

Behavior. The results are shown in Table 1. Differences between groups were tested by analysis of variance using the technique of planned contrasts (Hays, 1963): In number of avoidance responses, there were no significant differences between the unoperated and cortical control Ss $(F<1)$. Similarly, the differences between the dorsal and ventral caudate rats $(F=2.65)$ were not significant at the a priori selected probability level of .05 . It is interesting that the direction of these differences indicated that dorsal lesions were more disruptive than ventral lesions. The combined caudate group made significantly fewer successful avoidances than the combined control group $(F=5.67, \mathrm{df}=1 / 35$, $\mathrm{p}<.02$ ). For the mean number of trials taken to reach criterion analysis of variance by planned contrasts showed that the performance of the unoperated and cortical lesion rats did not differ significantly $(F<1)$. There was no significant difference between the dorsal and ventral caudate lesion rats $(F=1.75)$. It was found that the control rats reached criterion in significantly fewer trials than the caudate lesion rats $(F=8.25$, df $=$ $1 / 35, \mathrm{p}<.01)$.

Histology. At the conclusion of the experiment, the brain-lesioned rats were anesthetized and perfused intracardially, first with saline and then with a
saline-Formalin solution. After perfusion, the brain was removed from the skull and blocks of tissue containing the lesioned areas were cut from the brains. These blocks were mounted on a freezing-head microtome and sliced at 20-micron intervals. At levels 7.4, 8.6, and 9.0 anterior, the extent of tissue damage was sketched directly from the frozen block onto outlines traced from de Groot (1959).

The striatal lesions were situated in the central aspect of the anterior caudate-putamen complex. At sections 7.4 to $9.0 \mathrm{~mm}$ anterior, the $+1.0-\mathrm{mm}$ ventral level according to de Groot (1959) was selected as the separating point for ventral and dorsal lesions. To be classified as dorsal, lesions had to be superior to this point; to be classified as ventral, lesions had to be below this point. The destruction of tissue outside the striatum was minimal and involved in the extreme less than $5 \%$ of the total lesion. The only extrastriatal structures involved were the overlying subcortical white matter in some of the larger dorsal lesions and the nucleus accumbens septi in a few of the more extensive ventral lesions. Ss with lesions involving these extrastriatal areas appeared to perform no differently than those with lesions confined entirely to the caudate nucleus. Caudate nucleus lesions at levels between 7.4 and $9.0 \mathrm{~mm}$ anterior (De Groot, 1959) are shown in Fig. 1.

The frontal lesions were smaller than those described in earlier studies (Campbell \& Lynch, 1969; Kirkby, 1973). In all brains the lesions involved Areas 6 and 10 (Krieg, 1946). In a few cases, the damage extended into Area 4 and some lesions penetrated to the corpus callosum, but in no case was subcortical tissue encroached upon. The extent of the cortical lesions is shown in Fig. 1.

Various corticofugal and corticopetal fibers flow through the corpus striatum. This suggests the possibility that the changes in behavior observed in rats with lesions of the caudate were due to disruption of these pathways rather than to damage to the caudate nucleus itself. In the rat brain these fibers "en passage" are spread diffusely throughout the striatum and do not form the compact tracts found in carnivores and primates (Crosby, Humphrey, \& Lauer, 1962; Zeman \& Innes, 1963). Thus, although lesions as restricted as those in thepresent study (see Fig. 1) would be likely to transect some fibers, the majority of connections running through the caudate would remain intact. Furthermore, many of the fibers passing through the anterior caudate nucleus are connections between the frontal cortex and thalamus (Crosby et al, 1962). So, to this extent, the inclusion of a group of rats with lesions of the frontal cortex serves as a control procedure for possible damage to such fibers.

\section{Discussion}

The results indicated that in the rat, one-way avoidance learning was significantly impaired following lesions involving the dorsal or ventral aspect of the 
Fig. 1. Extent and location of lesions traced onto outlines from de Groot (1959), 7.4-9.0 $\mathrm{mm}$ anterior. Showing representa tive lesions of dorsal (A) and ventral (B) regions of the anterodorsal caudate nucleus and the dorsolateral frontal cortex (C).

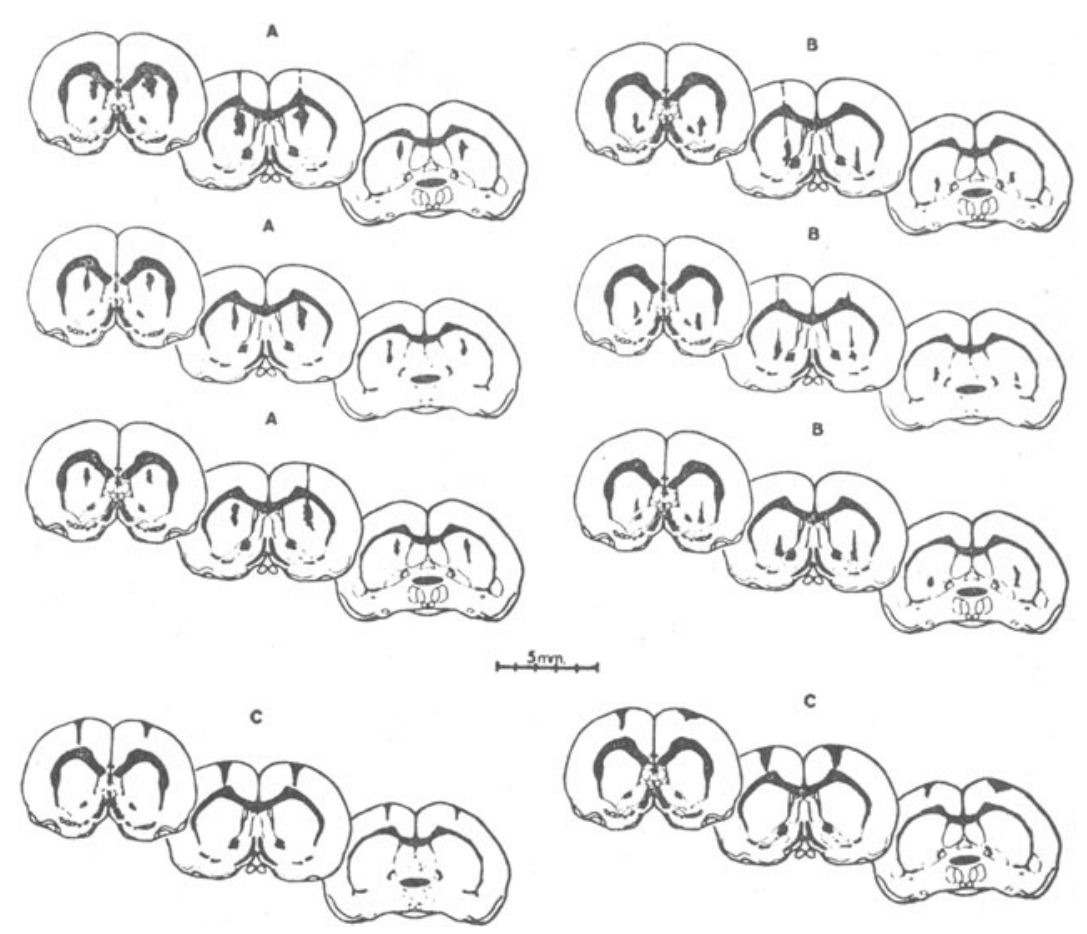

caudate nucleus. There were no significant differences in the learning of a one-way active avoidance task by rats with lesions in the dorsal aspect or the ventral aspect of the caudate nucleus. It is important to note that the direction of the differences indicated that dorsal damage was more disruptive than ventral damage. These findings suggest that the lack of deficits of the dorsal lesion rats in the Winocur and Mills (1969) study was not associated with the specific area of caudate damage. This leaves the second of the alternatives suggested in the introduction: The failure of Winocur and Mills to find significant avoidance deficits was due to a variable such as the size of the lesion, the method of statistical analysis, or some feature of the experimental procedure.

As the extent of caudate damage in the present experiment and the study of Winocur and Mills (1969) was much the same, it seems unlikely that the size of the lesions could explain the differing findings.

Marked avoidance deficits by caudotomized rats in the one-way situation were reported by Kirkby and Kimble (1968). A particular feature of the experimental procedure that differed in the Winocur and Mills and the Kirkby and Kimble studies was the level of electric shock used as the UCS. Whereas Kirkby and Kimble (1968) used 3.0 mA, Winocur and Mills (1969) used a much lower $0.4 \mathrm{~mA}$. In Experiment I of this study, deficits were found when $1.0 \mathrm{~mA}$ was used, and impaired one-way active avoidance behavior of caudotomized rats has been reported in other studies involving shock levels similar to this (Kirkby, 1969). It is possible that under conditions of very low shock, such as those used by Winocur and Mills (1969), one-way avoidance was not impaired in rats with lesions of the dorsal caudate nucleus. To test this hypothesis, Experiment II was carried out.

\section{EXPERIMENT II}

\section{Method}

The Ss were 28 male Wistar albino rats supplied by the C.S.I.R.O. Previously, the rats had been tested on a series of food-rewarded maze problems involving equivalent treatment for all Ss. Ten rats received dorsal caudate lesions, 9 rats received ventral caudate lesions, and 9 rats served as sham-operated controls. The electrode placements and current parameters for the caudate lesions were described in Experiment I. The sham operations involved the general surgical procedure; however, the electrode was not lowered below the dura and no neural tissue was destroyed. The size and location of the caudate lesions were similar to those outlined in Experiment I.

Testing commenced 6 weeks after surgery. At this time the rats were approximately 130 days old. The apparatus described in Experiment I was used. Except that the UCS intensities were set at .4 and $1.3 \mathrm{~mA}$, the task parameters were the same as in Experiment I. The Ss were trained to a criterion of $9 / 10$ correct responses on any one daily session of 10 trials. When this criterion was reached, training was terminated. Fourteen Ss were tested using a UCS of $4 \mathrm{~mA}$ ( 5 dorsal caudate, 4 ventral caudate, 5 sham-operated). The remainder were tested using $1.3 \mathrm{~mA}$. As in the previous experiment, the study was blind.

\section{Results}

The mean numbers of trials taken to reach criterion are shown in Table 2. Analysis of variance by planned contrasts revealed that the performance of the ventral and dorsal caudate lesion Ss did not differ significantly $(F<1)$. The sham-operated rats achieved criterion in significantly fewer trials than did the caudate-operated rats $(F=7.25, \mathrm{df}=1 / 22, \mathrm{p}<.02)$. For the sham rats, trials to criterion was the same for both 
Table 2

One-Way Active Avoidance Learning Under Conditions of High and Low Shock

\begin{tabular}{|c|c|c|c|c|c|c|}
\hline \multirow[b]{3}{*}{ Group } & \multicolumn{6}{|c|}{ Trials to Criterion } \\
\hline & \multicolumn{3}{|c|}{ High Shock } & \multicolumn{3}{|c|}{ Low Shock } \\
\hline & $\mathbf{N}$ & Mean & SD & $\mathbf{N}$ & Mean & SD \\
\hline Sham-Operated & 5 & 28 & 11.7 & 5 & 28 & 11.7 \\
\hline Ventral Caudate & 5 & 34 & 12.0 & 4 & 48 & 16.3 \\
\hline Dorsal Caudate & 5 & 30 & 7.1 & 5 & 54 & 4.9 \\
\hline
\end{tabular}

high and low shock conditions. The caudate lesion group performed significantly better under increased shock $(F$ $=4.56, \mathrm{df}=1 / 22, \mathrm{p}<.05)$. When the subgroups were further analyzed using the Mann-Whitney U test, it was found that the dorsal and ventral groups did not vary significantly under either low $(U=12)$ or high shock conditions $(\mathrm{U}=11)$.

\section{Discussion}

The results showed that the sham-lesioned rats learned the avoidance problem in significantly fewer trials than did the rats with lesions of the caudate nucleus. Under conditions of either high or low shock, the performance of the ventral caudate lesion group was not significantly different from that of the dorsal group. These findings are consistent with the results of Experiment I but do not support the hypothesis suggested by Winocur and Mills $(1969,1970)$.

It has been reported that lesions of the caudate nucleus increase the responsivity of the rat to changes in environmental stimulation (Kirkby, 1973). The results of the present experiment support this; although the variation in shock level did not alter the performance of the sham-operated animals, it did affect the rats with lesions of the caudate. It is interesting to consider these findings in the light of the inverted $U$ curve hypothesis (Hebb, 1955). In the present study the shock levels were set at 0.4 and $1.3 \mathrm{~mA}$. The lower level was selected because this was the intensity used by Winocur and Mills (1969). The upper level was selected simply because it was the highest intensity available on the instrumentation. On relative values, $1.3 \mathrm{~mA}$ is not a "high" level shock; as mentioned earlier, Kirkby and Kimble (1968) used a shock level of $3.0 \mathrm{~mA}$. It could be that, in terins of the inverted $U$ curve, 0.4 and $1.3 \mathrm{~mA}$ are similar in arousal-eliciting properties. Use of a higher level shock, such as $3.0 \mathrm{~mA}$, might have been enough to increase arousal to an extent that performance, crossing the hypothetical peak of the $U$ curve, would be further impaired.

It was decided to carry out another experiment. The purposes of this study were, firstly, to examine further the interaction between arousal and active avoidance learning and, secondly, to test the hypothesis of Winocur and Mills $(1969,1970)$ in regard to two-way active avoidance.

\section{EXPERIMENT III}

Two changes were made from the procedure used in the previous experiment. These changes concerned the difficulties of the task and the method of manipulating arousal. A two-way active avoidance task was used. It was thought that the increased difficulty of the two-way task (Bolles, 1970) would better reflect the active avoidance impairment of the caudate rats. Furthermore, this change allowed the testing of the Winocur and Mills (1969) hypothesis with regard to two-way active avoidance learning. Secondly, it was decided to manipulate arousal by varying conditions of food deprivation. This decision was based on the results of earlier investigations indicating that caudate-lesioned rats were hyperreactive to conditions of food deprivation (Kirkby, 1973).

\section{Method}

The rats tested in Experiment I served as Ss. The apparatus was that described in Experiment I. Two-way active avoidance training began 12 days after the final one-way acquisition session. Four days prior to the start of training, a 24-h food deprivation schedule was commenced for all Ss. The rats were fed in their home cages at 5:00 p.m., each receiving a tray of wet mash. Water was available at all times. Although no record of weight changes was kept, all Ss survived and none appeared ill or weakened during the experiment. Twenty rats (5 unoperated, 4 cortical control, 4 ventral caudate, 5 dorsal caudate) made up the nondeprived group; they were tested $30 \mathrm{~min}$ after eating. The remaining rats ( 5 unoperated, 5 cortical control, 6 ventral caudate, 5 dorsal caudate) were the deprived group; they were tested prior to eating. The differences in the numbers of the subgroups resulted from an error in the recoding of the Ss. The study was run blindly, and it wasn't until the histological evaluation that this error was uncovered.

Each $\mathrm{S}$ was given 20 trials a night for 5 successive nights. A trial commenced when the $S$ was placed in one compartment of the apparatus. Five seconds later, the guillotine door was opened and the tone sounded (UCS). Five seconds after this, a $1.0-\mathrm{mA}$ current was passed through the grid floor (CS). The $S$ could avoid the shock by moving through the door into the adjacent compartment in the 5-sec UCS-CS period. The UCS was terminated after $5 \mathrm{sec}$ or when the rat escaped to the other side of the apparatus. The $\mathrm{S}$ was allowed to remain in the safe compartment for $30 \mathrm{sec}$ before the next trial was commenced. As before, the CS and UCS were activated and the animal moved to the other side of the apparatus. On the first trial of the two-way avoidance training, all rats were started in the compartment that had been "safe" in Experiment $I$.

\section{Results}

The mean numbers of avoidances in 100 trials are shown in Table 3 . When the group differences were tested by analysis of variance, planned contrasts, it was found that the performances of the unoperated and cortical control groups were not significantly different $(F=1.6)$. Of the caudate rats, the dorsal lesion group made significantly fewer avoidances than the ventral lesion group $(F=11.6, \mathrm{df}=1 / 31, \mathrm{p}<.01)$. A comparison of the scores of the combined control groups and the combined caudate groups indicated that the controls made significantly more avoidances $(F=$ 
9.9, $\mathrm{df}=1 / 31, \mathrm{p}<.01)$. An examination of performances under conditions of deprivation vs nondeprivation using Mann-Whitney $U$ tests indicated that none of the four groups was significantly affected. Further analysis of the subgroups showed that the rats with lesions of the dorsal caudate were significantly inferior to the ventral lesion Ss for both deprivation $(U=$ $5, \mathrm{p}<.04)$ and nondeprivation conditions $(\mathrm{U}=2$, $\mathrm{p}<.04)$.

\section{Discussion}

The present findings showed that for two-way active avoidance, rats with lesions of the dorsal caudate nucleus were significantly more impaired than rats with lesions of the ventral caudate nucleus. This finding is not in agreement with the Winocur and Mills $(1969,1970)$ hypothesis that dorsal caudate lesions do not disrupt active avoidance learning.

The finding that the ventral caudate lesion rats were superior to the dorsal caudate lesion rats under conditions of nondeprivation appears inconsistent with the findings of Neill and Grossman (1970). They reported that over their total testing schedule, 20 trials per day for 14 days, the two-way active avoidance performances of dorsal and ventral caudate groups did not differ significantly. Two points should be made about this finding. Neill and Grossman (1970) commented that the performance of their dorsal group was improved by the inclusion of animals with lesions located specifically in the dorsomedial corner of the caudate. These Ss performed as efficiently as unoperated rats. Secondly, the present results are based on avoidance performance over 100 trials, 20 per day for 5 days. Reading off the graph of mean scores provided by Neill and Grossman (1970; Fig. 2) indicated that, within the initial 100 trials, their dorsal lesion rats performed less than $60 \%$ of the avoidance made by the rats with lesions of the ventral striatum.

The present findings, supported by those of Neill and Grossman (1970), suggest that for at least some avoidance learning situations, the dorsal aspect of the caudate nucleus could be more important than the ventral aspect. The particular importance of the dorsal aspect of the anterior caudate nucleus in learning tasks has been suggested in other studies. Divac, Rosvold, and Szwarcbart (1967) reported that alternation learning in monkeys was disrupted by anterodorsal lesions but not by damage to other areas of the caudate. The anterodorsal caudate, particularly, has been implicated in delayed response learning in cats (Divac, 1968). Recent work in our laboratory has shown that Hebb-Williams maze learning in the rat is disrupted by dorsal but not ventral lesions of the anterior caudate nucleus (Kirkby, 1972, unpublished study). It is not unexpected that lesions involving different parts of the corpus striatum should vary in effect. The dorsal and ventral aspects of the striatum, for example, are not homogeneous regarding connections with other neural
Table 3

Two-Way Active Avoidance Learning Under Conditions of Food Deprivation

\begin{tabular}{|c|c|c|c|c|c|c|}
\hline \multirow[b]{3}{*}{ Group } & \multicolumn{6}{|c|}{ Number of Avoidances in 100 Trials } \\
\hline & \multicolumn{3}{|c|}{ Deprived } & \multicolumn{3}{|c|}{ Nondeprived } \\
\hline & $\mathbf{N}$ & Mean & SD & $\mathrm{N}$ & Mean & SD \\
\hline Unoperated & 5 & 26.6 & 4.9 & 5 & 39.0 & 16.5 \\
\hline Frontal Cortex & 5 & 36.0 & 16.3 & 4 & 46.8 & 16.6 \\
\hline Ventral Caudate & 6 & 21.7 & 5.3 & 4 & 45.0 & 21.2 \\
\hline Dorsal Caudate & 5 & 8.6 & 12.9 & 5 & 11.0 & 8.8 \\
\hline
\end{tabular}

structures (Knook, 1965). Additionally, there is evidence that each of these areas has specific sensitivities to different neurotransmitters (Neill \& Grossman, 1970).

We were surprised that the active avoidance performance of the unoperated rats was not significantly affected by conditions of food deprivation. This finding does not appear consistent with the earlier report of Thomas and Slotnick (1963). There is, however, an important difference in the experimental procedures carried out by Thomas and Slotnick and those in the present study. While the rats tested by Thomas and Slotnick (1963) were naive to avoidance learning, the Ss in the present study had been trained previously on a one-way active avoidance task. Although not significant, the differences between performance under deprivation and nondeprivation were, for all groups, consistently indicative of increased impairments under conditions of deprivation. Increased impairment could occur if the arousal elicited by deprivation augmented the arousal elicited by the avoidance situation to such an extent that the peak of the hypothetical inverted $U$ course was crossed and performance reduced (Hebb, 1955). With this in mind, it is interesting to note that the performances of the control groups under deprivation compared to nondeprivation were reduced by $26 \%$. For the caudate rats, deprivation reduced performance by 54\%. Although these findings cannot be tested statistically, they are suggestive of increased reactivity in the caudate-lesioned Ss.

\section{GENERAL DISCUSSION}

The experiments carried out in this study showed that lesions of the caudate nucleus disrupted one-way and two-way active avoidance learning in the rat. This conclusion is consistent with the findings of Kirkby and Kimble (1968) and Kirkby (1969) regarding one-way avoidance and with the findings of Green, Beatty, and Schwartzbaum (1967) and Neill and Grossman (1970) regarding two-way avoidance. The present findings are not in agreement with those of Winocur and Mills (1969) or those of Albert and Bignami (1967).

In the Albert and Bignami (1967) study, rats with lesions in various parts of the brain were tested on a two-way active avoidance task. The testing was carried out in an automated shuttlebox in which spatial cues 
were minimized by the use of diffuse illumination and the absence of a central partition dividing the apparatus into discrete compartments. Albert and Bignami (1967) reported that rats with lesions of the caudate nucleus performed no differently than sham-lesioned Ss. It is interesting that they also found no deficits in rats with lesions of the posterior medial cortex. Avoidance deficits in rats with lesions in this area have been reported by several other investigators (Green, Beatty, \& Schwartzbaum, 1967; Thomas \& Slotnick, 1963; Trafton, 1967). It may be that the particular apparatus and task parameters used by Albert and Bignami (1967) were such that any possible avoidance deficits in rats with lesions of the caudate or the posterior medial cortex were not revealed.

Winocur and Mills (1969) failed to find one-way avoidance deficits in rats with lesions of the dorsal aspect of the caudate nucleus and hypothesized that active avoidance learning was impaired by ventral but not dorsal caudate lesions. In the present study, it was found that for one-way active avoidance, lesions of the ventral caudate were not more disruptive than lesions of the dorsal caudate. For the two-way avoidance situation, these findings are supported by the report of Neill and Grossman (1970). For the one-way situation, the present findings are consistent with the results of an earlier study by Kirkby and Kimble (1968). In Experiment II of their study, Kirkby and Kimble found that rats with lesions of the anterior caudate nucleus were impaired in learning to vacate a compartment to avoid shock. The lesions in these rats were described as "placed rather dorsal so that typically $30-40 \%$ of the lesion involved cortical and callosal tissue [p. 222]," and the striatal damage as illustrated by Kirkby (1967) was contained in the dorsal half of the caudate-putamen complex.

The present experiments and the Neill and Grossman (1970) studies incorporated a ventral as well as a dorsal group of caudate lesion rats. In this way, these investigations were more adequately controlled than those of Winocur and Mills (1969). As the present experiment and that of Neill and Grossman (1970) are in accord, and as they are further supported by the findings of Kirkby and Kimble (1968), it seems parsimonious to reject the hypothesis of Winocur and Mills $(1969,1970)$. learning. Psychological R eview, 1970, 77, 32-48.

Campbell, B. A., \& Lynch, G. S. Cortical modulation of spontaneous activity during hunger and thirst. Journal of Comparative \& $\mathrm{Phy}$ siological Psychology, 1969, 67, 15-22.

Crosby, E. C., Humphrey, T., \& Lauer, E. W. Correlative anatomy of the nervous system. New York: Macmillan, 1962. de Groot, J. The rat forebrain in stereotaxic coordinates. Amsterdam: Noord-Hollandsche Uitgevers Maatschippij, 1959

Divac, I. Effects of prefrontal and caudate lesions on delayed response in cats. Acta Biologiae Experimentalis (Warsaw), $1968,28,149-167$.

Divac, I., Rosvold, H. E., \& Szwarcbart, M. K. Behavioral effects of selective ablation of the caudate nucleus. Journal of Comparative \& Physiological Psychology, 1967, 63, 184-190.

Green, R. H., Beatty, W. W., \& Schwartzbaum, J. S. Comparative effects of sep to-hippocampal and caudate lesions on avoidance behavior in rats. Journal of Comparative \& Physiological Psychology, 1967, 64, 444-452.

Hays, W. L. Statistics for psychologists. New York: Holt, Rinehart \& Winston, 1963.

Hebb, D. O. Drives and the C.N.S. (conceptual nervous system). Psychological Review, 1955, 62, 243-254.

Kirkby, R. J. Caudate nucleus lesions and maternal behavior in the rat. Psychonomic Science, 1967, 9, 601-602.

Kirkby, R. J. Caudate nucleus lesions and perseverative behavior. Physiology \& Behavior, 1969, 4, 451-454.

Kirkby, $R$. J. The caudate nucleus and active avoidance. A comment on the report of Winocur and Mills. Psychonomic Science, 1970, 18, 260.

Kirkby, R. J. The caudate nucleus and arousal in the rat. Journal of Comparative \& Physiological Psychology, 1973, 85, 8296.

Kirkby, R. J., \& Kimble, D. P. Avoidance and escape behavior following striatal lesions in the rat. Experimental Neurology, 1968, 20, 215-227.

Knook, H. L. The fibre-connections of the forebrain. Assen: V an Gorcum, 1965.

Krieg, W. J. Connections of the cerebral cortex. I. The albino rat. A. Topography of the cortical areas. Journal of Comparative Neurology, 1946, 84, 221-259.

Neill, D. B., \& Grossman, S. P. Behavioral effects of lesions or cholinergic blockage of the dorsal and ventral caudate of rats. Journal of Comparative \& Physiological Psychology, 1970, 71, 311-317.

Romanovskaya, E. A. Certain consequences of destroying the caudate nuclei in rabbits and dogs. Bulletin of Experimental Biology \& Medicine, 1957, 44, 1066-1069.

Thomas, G. J., \& Slotnick, B. M. Effects of lesions of the cingulum on maze learning and avoidance conditioning in the rat. Journal of Comparative \& $\mathrm{Phy}$ siological Psychology, 1962, 55, 1085-1091.

Thompson, R. L., \& Mettler, F. A. Permanent learning deficit associated with lesions in the caudate nuclei. American Journal of Mental Deficiency, 1963, 67, 526-535.

Trafton, C. L. The effects of lesions in the septal area and cingulate cortical areas on conditioned suppression of activit? and avoidance behavior in rats. Journal of Comparative : Physiological Psychology, 1967, 63, 191-197.

Turner, E. A. Cerebral control of respiration. Brain, 1954, 77, 448-486.

Winocur, G., \& Mills, J. A. Effects of caudate lesions on avoidance beahvior in rats. Journal of Comparative \& Physiological Psychology, 1969, 68, $552-557$.

Winocur, G., \& Mills, J. A. The caudate nucleus and active avoidance. Reply to Kirkby. Psychónomic Science, 1970, 18, 270.

Zeman, W., \& Innes, J. R. Craigie's neuroanatomy of the rat. New York: Academic Press, 1963.

\section{REFERENCES}

Albert, M., \& Bignami, G. Effects of frontal, median cortical, and caudate lesions on two-way avoidance learning by rats. Physiology \& Behavior, 1968, 3, 141-147.

Bolles, R. C. Species-specific defense reactions and avoidance
(Received for publication November 15, 1973; accepted November 29, 1973.) 